\title{
On Hierarchical Development of Graphic Creative Thinking
}

\author{
Linxue Lv \\ The Department of art and design, Teachers' College \\ Beijing Union University \\ Beijing, China \\ sftlinxue@buu.edu.cn
}

\author{
Xilong Jiang \\ The Department of art and design, Teachers' College \\ Beijing Union University \\ Beijing, China \\ xilejoy945@126.com
}

\begin{abstract}
In the face of fierce competition and the future of the world, the teaching of art design should conduct all-round and cautious thinking and decision-making regarding how to improve the all-round quality and creative ability of students. The course of graphic creative focuses on the organic combination of "theory and practice", "foundation and profession" and "classroom and society" to explore a unique teaching mode for the cultivation of innovative talents of art design.
\end{abstract}

Keywords-graphic creative; creative thinking; hierarchical development

\section{INTRODUCTION}

In the face of opportunities and challenges in the $21^{\text {st }}$ century, we must build a teaching mode that fits the education of art design in China. With scientific attitude, innovative awareness and sacrifice, the outdated teaching methods must be broken through for the exploration of the educational rules and patterns of art design in depth and for the solid foundation of educating art design talents of high quality.

The course of Graphic Creative (GC hereinafter) is a new teaching mode developed gradually out of historical teaching reforms of the college over years. With scientific principles and flexible methods, the course motivates the subjective initiative of students, nurses and improves their overall qualities and creative ability. Guided by modern and frontline ideas, the course, assisted by huge quantity of graphic materials, combines boring theories with professional design, in an organic, lively and illuminating manner, so that students can truly understand the nature of art design, determine their direction of efforts, master methods and improve their systematic control of art design.

\section{OPENING NeW ThINKING OF ART DeSIGN WITH SCIENTIFIC PRINCIPLES}

Innovation is the essence of art design, and creative thinking is the soul. The nursing of creative ability is a comprehensive embodiment of mutual enhancement between the function of human brain, the knowledge system and the thinking method. The course of Graphic Creative, correspondingly, guides students into full command of the principles of creative thinking through such aspects as scientific use of the brain, construction of the knowledge system and employment of scientific thinking.

\section{A. Scientific Use of the Brain}

Human brain is a wonderful "epitome of the universe", and a giant treasury of initiative resources. Understanding the unlimited potential of the brain is the premise to nurse and improve creative thinking. GC broadens the horizon of students by showing the historical changes, structural principles and functional areas of the brain. Understanding the green resource everyone has-the brain-provides students with an infinite space of self-development.

\section{B. Constructing Knowledge System}

Einstein once said: "Creative ability equals the product of past knowledge and imagination." Knowledge is an immense system constructed out of concepts gained by humans trying to understand the world, and it is usually called knowledge system. It is an organic system, and it takes flexible understanding to form the power of fission and fusion, and to make full use of it.

Command of knowledge of art design depends on a rational and orderly structure, viz. to form an orderly knowledge system. With unique perception of the rules between art design and relevant disciplines, natural use of knowledge can be attained in the process of innovation [1]. Systematic and orderly knowledge is the premise to efficient innovation. Belinsky once pointed out: "The most common feature of science is system." The command of the system of art design knowledge, in fact, is an all-round and systematic command of the inner rules of art design and relevant disciplines. If knowledge in command is but bits and ends, the whole-innovative function of knowledge can never be brought into play. On the basis of imparting professional knowledge, GC explains interrelations between knowledge systems in a thorough and cubic manner, guides students to analyze, compare, understand and command, and to fuse all that they have learnt into an integrated knowledge system, which will be a solid foundation for the nursing of creative thinking.

\section{Establishing Scientific Thinking}

"Success is the success of notion and ways of thinking." Knowledge system (KS) is a powerful support of creative thinking. However, the quantity of knowledge does not equal the ability to create. Creative ability requires not only a complete KS, but also scientific thinking method.

Scientific thinking method refers to particular activity of the conscious motivated by self-fulfillment and social value 
orientation for the proposition and solution of problems in accordance with the developmental rules of the objective world; it is a thinking pattern that embodies certain contents and methods of thinking. The establishment of scientific thinking is a process of constant self-adjustment, selfcomplementation and self-improvement on the basis of scientific rules, viz. the negation and development of previous modes of thinking in response to the advancement of time and the development of science. It also requires good conditions and status that maintain the fluency of graphic, logic and intuitive thinking, which effectively solves a series of problems in art design.

Thinking method is the core issue of the science of thinking as well as the important part of GC, which starts from the concepts of thinking methods, explicating the nature, type, function and operative procedure of thinking method. Through sense training, dedicated research, interactive Q\&A, artistic expression and other training methods, potentials of students are stimulated and desires to create are motivated. Starting from students' personal experiences, theories and practices are ingenuously fused to moisten the boring theories so that students would crave for, instead of being disgusted by, them. With passion in their trainings, full unfolding of the art design course system will have a solid foundation.

\section{HIERARCHICAL DEVELOPMENT OF GC THINKING (GCT HEREINAFTER)}

To nurse and develop students' drive and ability of innovation is to combine scientific thinking principles with art training for the overall development of their wisdom and qualities, and to open up their portal of wisdom according to their characteristics. Creative thinking involves the overall development of students' qualities, and, GC as an "enlightening" course stresses on the use of students subjective initiative and the cultivation of their comprehensive qualities. In class, a lively and harmonious environment for learning is created to motivate students' latent awareness of the self, their passion in learning and their development of healthy personalities.

Practice produces truth; without practice, there cannot be innovative thinking. Based on this, GC stresses on students having thematic training, viz. given plots and situations, so that they can acquire actual experiences at different levels of actual practice and gain insight into the basic principles of scientific thinking, and, eventually, become more creative and better qualified for their work and life. levels:

GC provides its students with pinpointed practices at four

\section{A. Quiz}

Quiz in class designates theme, conditions, time and scientific principles of thinking to guide students through the process of divergent thinking and comprehensive thinking so that their minds are exposed to multiple ways of thinking and that they can have the habit of thinking critically. Class teaching does not pursue "standard answer" anymore, but "best solution". Thus students' solution of the problem can be expanded, and students can be better at identifying, analyzing and solving problems with the best methods and ways. Through training students' ability to express, they can make flexible use of body language, drawing language and design language and other formal elements for organization and expression, to complete training of creative thinking and to nurse unlimited creative potentials and ability of students within limited conditions.

\section{B. Interactive $Q \& A$}

Through interactive $\mathrm{Q} \& \mathrm{~A}$ between students and teachers, passive learning is turned into active thinking. Not only does this enhance students' verbal skills, but also their confidence and adaptability in front of the public. Through flexible and varying interactive Q \& A, students come to master multiple ways of thinking and expressing, and to understand the basic principles of art design, and their passion and inspiration of art design can be stimulated.

\section{Establishing Scientific Thinkin}

Organizing and guiding students to plan thematic debates, where they can collectively communicate and discuss with each other; with collective thinking, students can experience training and various class teaching forms and make full use of their initiatives. Through debates or discussion of relevant frontier theories' typical questions, a good academic context can be formed, and students' horizon can be broadened, and their notion and methods of art design can be further understood and commanded.

\section{Social Practices}

Actively organize students to participate in social design practices and various creative contests so that class teaching can be closely associated with social practice. Social practice takes participation and coordination, and in it students can get exercises that are absent in classroom. Students are urged to face reality and to use the principle and method of scientific thinking from multiple aspects and angles to analyze and understand problems, and to use multiple methods and ways to seek the best design. GC, through social practices, further elevates students' personal experience, in which they can find their value and a broad space for the study and practice of art design.

GC extends classroom to outside of classroom, then to society. Passive reception turns into active learning......through multiple dimensions, a wide variety of practical situations are constructed for students to improve their creative thinking in different contents and forms of the practice link. In the actual experience of creative design, they open the "portal of wisdom" for creative thinking.

\section{Constructing New Modes For the Cultivation OF ART DESIGN MINDS}

GC is an all-round and systematic teaching process. The new mode it establishes realizes the turn from occupational education to quality education. With constant efforts over long time, a unique course has been formed, and its characteristics are as follows: 


\section{A. Innovation of Course Theory}

This course aims at the innovation of design concept and design development, and makes explorative study and comprehensive use of the thinking science, study of creation, semiotics, methodology and system theory in such frontline disciplines as philosophy, aesthetics, psychology and communication studies. With the interactive function of consciousness, sub-consciousness and unconsciousness in psychology, the active role of thinking is explored to effectively stimulate students' potentials in design, to automatically mobilize "visual thinking" in the learning process of art design, to use such artistic means as "telepathy", to explore the broad space of "collective unconscious", and to pursue the creative effect that is "within reason and outside of expectation". With students of different levels, the interactive role of three levels, "technique", "concept" and "rule", in art design, a new education system of art design is established.

\section{B. Science of Curriculum}

Curriculum must be closely associated with the trend of social development and the quality of students so that the greatest potential of designers can be made full use of. With flat knowledge system of students at present, students' initiative in learning is motivated, their target and methods of learning are clarified, and their own knowledge system is established; the joint between "self-fulfillment" and "social value" and their transition will be sought after. Through scientific curriculum, a complete structure of design concepts is built, a rational $\mathrm{KS}$ of design is established; students potentials and self-awareness are developed, creative passions are motivated, and professional theory and skills are mastered; all in all, a course system that fully develops and nurses students comprehensive qualities should be formed.

\section{System of Course Structure}

Theoretical foundation and design practice in GC are independent of and interdependent on each other. Theory, practice and knowledge and skills of different disciplines are joined to form the system of professional knowledge and course structure. The course stresses on the development of frontline theory of design, organic combination of scientific theories with professional skills; establishes the systematic framework of course structure, knowledge structure and teaching structure so that students can clearly understand the direction, scope, methods and ways of art design, break the single skill and flat knowledge system, and acquire systematic knowledge through scientific course arrangement. $\mathrm{GC}$ is a component of the system, and a consistent link as well. Only by establishing a scientific system of teaching and courses can students be helped to establish their own system of professional knowledge and skill, their qualities be improved and art design talents be contributed to society.

\section{Effectiveness of the Content of the Course}

With its property and professional features, GC tries to combine its training and assignments with design contests at home and abroad and with social practice so that real effects can be achieved through actual operation and competition, which stimulate students' eagerness to create and to design. In actual exercise and test, students can use basic principles and methods to obtain actual success, and keep surpassing themselves in the experience of success and failure on their way to the success of art design.

\section{E. Ductility of Course Effect}

The value of art design lies in the innovative development out of the combination of science and art. Through GC's ductility, the crossing of various disciplines as well as the fusion of knowledge, skill and thinking methods are stressed on to cause the change from quantity to quality. Only then will art design exercise its due social value.

Ductility of the course is to be seen in the vertical and the horizontal dimension. Vertically speaking, this course establishes a vertical teaching system of art design, and the developmental history of art design at theoretical level. Tracing its origin and identifying its developments, the course seeks rules and forms the vertical extension of the course in the joining of three levels, viz. technique, concept and rules. Horizontally speaking, based on the fusion of international cultural comparison, development of modern front concepts and the value orientation of Chinese cultural spirit, and, in the organic combination of art design's direction, principle and executive means, the horizontal extension of teaching is formed. With the vertical and horizontal extension of GC, which forms an axis system, students can make quick and accurate use of "foothold", produce "point of creativity" and develop "point of value". Effectively linking with other disciplines and professional courses to form a dynamic and complete teaching system, and reinforcing the interactive link in the teaching of theory and practice in art design can elicit strong responses from students, who actively and passionately participate in teaching and learning. A new and benign teaching mode is formed, making positive contribution to the reform and development of art design education.

True point of the education of art design lies in nursing innovative minds. In the face of fierce competition and the future of the world, the teaching of art design should conduct full and cautious considerations and decision-makings at the level of cultivating students' full quality and creative competence. As a college dedicated to training minds of art design, we should carry on the sacred mission assigned to us by society by making a solid foundation for students who are about to enter an extremely spacious creative space, and by cultivating more and better talents of art design.

\section{ACKNOWLEDGMENT}

1. Education and teaching research and reform project of Beijing Union University: study on talent cultivation of art design major in the application-oriented university.

2. Topic of "Twelfth five-year plan" higher education and scientific research planning of Beijing Association of Higher Education: study on talents cultivation model for participation of students with major of art design in design projects of enterprises (Topic No.: BG125YB024).

3. 2011 topic of "Twelfth five-year plan" for education and science in Beijing: study on the model of participation of 
students with major of art design in design practice projects of enterprises (Topic No.: DEB11100)

\section{REFERENCES}

[1] Liu Guanzhong,"Creative Artistic Personnel Training Under the Guidance of Systematical Science[J]". Hundred Schools in Art, 2006(3):14-19.
[2] LI Jian, "From Psychological Aspects : How to Cultivate Creative Ability in Design Education [J]". Journal of Tonghua Normal University, 2008(5):61-63.

[3] Yan Danping, "Construction of Geological Practice Teaching System at Variable Level of The Undergraduate Stage [J]", Chinese Geological Education, 2009(1):65-68. 